\title{
Multi-objective Optimization of Locator Layout of Side-body Panel Based on RSM
}

\author{
XIA Yu-feng ${ }^{1, a}$, Ren $\mathrm{Li}^{1, \mathrm{~b}}$, YE Cai-hong ${ }^{1, \mathrm{c}}$ Wang $\mathrm{Li}^{1, \mathrm{~d}}$ \\ School of Material Science and Engineering, Chongqing University, Chongqing 400044, China \\ arenli1991@cqu.edu.cn, ${ }^{\text {b2}} 20130902005 @ c q u . e d u . c n,{ }^{c} w i l l y @$ cqu.edu.cn, dxuqiang223@ 163.com
}

Keywords: assembly quality; locator layout; RSM; multi-objective optimization; 3DCS

\begin{abstract}
In order to study the influence of locator layout on assembly quality, the side-body outer panel of auto B pillar was chosen as the object. Based on response surface methodology (RSM) and 3DCS, the quadratic response surface models were built up. The multi-objective function was optimized to get the best combination of locating parameters by Design-Expert software, that is, the coordinate values of locator blocks were L1x=1375 mm, L2x=1560 mm, L3z=325 mm, L4z=349 $\mathrm{mm}$. The numerical simulation results by 3DCS show that compared with the assembly results of initial locator layout, the optimization objectives were decreased by $35.2 \%, 22.9 \%$ and $23.6 \%$ respectively, meanwhile the superb rate was reduced to a qualified range, effectively solving the problem of excessive gap in the traditional assembly process. The production practice results further prove the feasibility of the methody.
\end{abstract}

\section{INTRODUCTION}

Along with the development of automobile industry, improving the assembly quality of B pillar has become a hot issue [1]. As the parts of B pillar are U-shaped stampings with larger size, thinner material, the assembly quality have enormous impact on the car's wind noise, sealing and security [2]. Most of the traditional method have focused on the field of selecting locators empirically and optimizing through the way of changing manufacturing variations or tolerances allocation. However, the adjustment of manufacturing tolerances will inevitably lead to increased costs, and a large amount of work, but also can't guarantee the accuracy of the results [3].

In recent years, reducing the assembly deviation by optimizing the locator layout of part has become a very effective optimization design method [4]. Cai et al. [5] put forward an optimization method of pins layout for the locating process of sheet metal, which can remarkably decrease the deviation. Huang et al. [6] analyzed the robustness of multi-station assembly process under fixture layout using a continuous space-filling method, and obtained the robust design of pin-hole layout of sheet metal assembly process based on number theory method. Wen et al [7] studied the assembly robustness of automobile headlight under different locator layout based on 3DCS and presented a pin-hole layout scheme, which has the smallest assembly deviation. However, the majority of previous researches were devoted to the robust design of pin-hole layout, to find the layout scheme which was not sensitive to noise factors, but it's not certain that the assembly deviation will be minimal.

In view of this, this paper presented the method of multi-objective optimization, and response surface methodology was firstly applied in assembly locating process. Combined with software 3DCS, the mathematical models of the locating parameters was established. Finally, the best layout scheme was obtained by analyzing the interaction between these coordinate parameters. Researchers can conduct robust design on this basis in order to further improve the assembly efficiency.

\section{THE INTRODUCTION OF PARTS}

The three-dimensional structural model of the B-pillar is shown in Fig. 1, and side-body outer panel is the middle part of the assembly process. For rigid parts, "3-2-1" locating principle was 
usually used in the assembly process. The side-body outer panel is flexible sheet metal parts, so the 4-2-1 locating principle was adopted. L1, L2, L3 and L4 are respectively on behalf of the positions of the locating blocks on part. P1 and P2 are the position of the two pins. $\mathrm{P}_{\mathrm{r}}$ is the measurement point. This paper was mainly aimed at multi-objective optimization of these locating blocks.

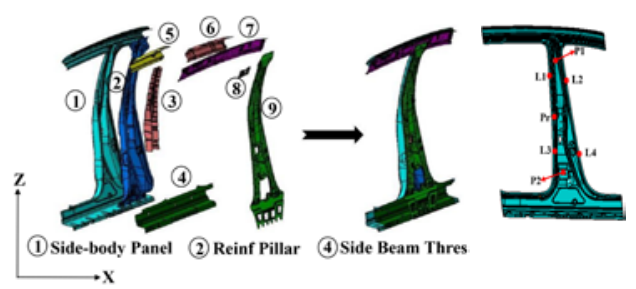

Fig. 1 Three-dimensional assembly model of B-pillar

\section{RSM MULTI-OBJECTIVE OPTIMIZATION}

\section{Coordinates Analysis of Locating Blocks}

Before using the RSM, it's better to determine a reasonable number of factors and the corresponding levels [8]. In order to acquire the coordinate range of the locating blocks, the relationship between the deviation of measuring point and coordinates should be analyzed at first. The assembly was simulated in 3DCS by taking the coordinates of locators as independent variables, taking the deviation of Pr along different directions as dependent variables. Then the ORIGIN software was used to fit the simulation results, and the curves of the relationship between them were build. Limited to the space, only the diagram of L1 and L2 were displayed in Fig. 2.
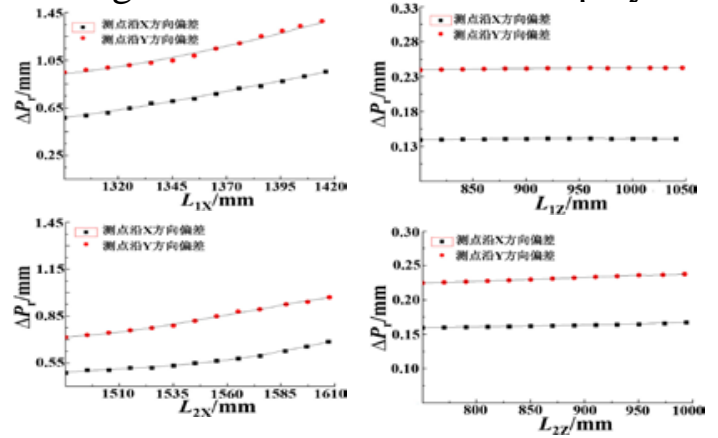

Fig. 2 Relationship between $\triangle \operatorname{Pr}$ and coordinates

It's not difficult to realize that the changes of coordinates along different directions have diverse influence. For example, the X direction changes of L1 and L2 have great influence while there are no obvious effect on $\mathrm{Z}$ direction. The $\mathrm{Z}$ direction changes of L3, L4 make a big difference, but the $\mathrm{X}$ direction can be neglected. This paper was mainly aimed at optimizing the $\mathrm{X}$ direction of L1\&L2, and $\mathrm{Z}$ direction of L3\& L4.

\section{Experiment Design}

In order to unify the test parameters, "Lab" is used to indicate the b direction of block $a . L_{1 \mathrm{x}}$, $L_{2 \mathrm{x}}, L_{3 \mathrm{z}}$ and $L_{4 \mathrm{z}}$ were expressed as A, B, C and D. Corresponding to point Pr, d0 was selected as the optimization objective. In order to guarantee the reliability of the results, $\mathrm{d} 1$ and $\mathrm{d} 2$ were selected as shown in Fig. 3. According to the experience design of locator layout, the range values of $L_{1 \mathrm{x}}, L_{2 \mathrm{x}}$, $L_{3 z}$ and $L_{4 z}$ were finally determined shown in Table 1 .

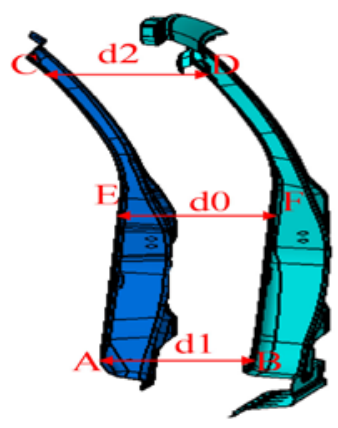

Fig. 3 Gap between side body panel and reinforce pillar 
TABLE 1 The optimized scope of variables

\begin{tabular}{|c|c|}
\hline Variables & Range \\
\hline $\mathrm{A} / \mathrm{mm}$ & {$[1320,1420]$} \\
\hline $\mathrm{B} / \mathrm{mm}$ & {$[1510,1610]$} \\
\hline $\mathrm{C} / \mathrm{mm}$ & {$[200,400]$} \\
\hline $\mathrm{D} / \mathrm{mm}$ & {$[200,400]$} \\
\hline
\end{tabular}

There are four optimization variables and five levels of each in this paper. Therefore the regression coefficient of the quadratic response surface model was total 15 . In order to simplify the program, the experiment was carried out by using Design-Expert v8.0 software and the factor level was shown in Table 2 [9]. The 3DCS software was used to complete the follow-up response surface analysis. Some results were shown in Table 3.

TABLE 2 The levels of factors

\begin{tabular}{|c|c|c|c|c|}
\hline Levels & $\mathrm{A} / \mathrm{mm}$ & $\mathrm{B} / \mathrm{mm}$ & $\mathrm{C} / \mathrm{mm}$ & $\mathrm{D} / \mathrm{mm}$ \\
\hline-2 & 1320 & 1510 & 200 & 200 \\
\hline-1 & 1345 & 1535 & 250 & 250 \\
\hline 0 & 1370 & 1560 & 300 & 300 \\
\hline+1 & 1395 & 1585 & 350 & 350 \\
\hline+2 & 1420 & 1610 & 400 & 400 \\
\hline
\end{tabular}

TABLE 3 Part of test program and results

\begin{tabular}{|c|c|c|c|c|c|c|c|}
\hline No. & A & B & C & D & d0 & d1 & d2 \\
\hline 1 & -1 & 1 & 1 & 1 & 0.5011 & 0.5106 & 0.5236 \\
\hline 2 & 1 & -1 & 1 & -1 & 0.4719 & 0.4638 & 0.5217 \\
\hline 3 & 0 & 0 & 0 & 0 & 0.4756 & 0.4816 & 0.4839 \\
\hline$\vdots$ & $\vdots$ & $\vdots$ & $\vdots$ & $\vdots$ & $\vdots$ & $\vdots$ & $\vdots$ \\
\hline 27 & -1 & -1 & 1 & 1 & 0.4913 & 0.4753 & 0.4795 \\
\hline 28 & 0 & 0 & 0 & 0 & 0.4769 & 0.4965 & 0.4836 \\
\hline 29 & -1 & 1 & -1 & -1 & 0.4732 & 0.4886 & 0.4962 \\
\hline
\end{tabular}

\section{Response Surface Model and Result Analysis}

The quadratic polynomial regression model was used to establish the prediction model of $\mathrm{d} 0, \mathrm{~d} 1$ and $\mathrm{d} 2$.

The quadratic polynomial regression model of four factors A, B, C, D can be described as follow:

$$
y=a+\sum_{i=1}^{n} a_{i} x_{i}+\sum_{i=1}^{n} a_{i i} x_{i}^{2}+\sum_{i=1}^{n-1} \sum_{j>1}^{n} a_{i i} x_{i} x_{j}+\varepsilon .
$$

According to (1), the least square method was used to conduct numerical analysis. Finally, the response surface function of d0, d1 and d2 were obtained, as shown in (2)-(4):

$$
\begin{aligned}
& d 0=0.57-0.0059 A+0.0063 B-0.0081 C+0.075 D+ \\
& 0.042 A C-0.049 A D+0.018 B C+0.013 B D+0.018 C D
\end{aligned}
$$

$-0.0032 A^{2}-0.007 B^{2}-0.03 C^{2}-0.05 D^{2}$

$d 1=0.76-0.0725 A+0.00525 B-0.0365 C-0.075 D$

$-0.05 A B-0.035 A C+0.02 A D-0.032 B C-0.027 B D$

$-0.022 C D-0.075 A^{2}-0.012 B^{2}-0.003 C^{2}-0.011 D^{2}$.

$d 2=0.68-0.0072 A+0.0075 B-0.0076 C-0.021 D+$

$0.001 A B+0.002 A C-0.006 A D-0.0023 B C+0.07 B D$

$+0.005 C D-0.004 A^{2}-0.003 B^{2}-0.0042 C^{2}-0.031 D^{2}$.

In order to verify the validity of the models mentioned above, the variance analysis of $\mathrm{d} 0, \mathrm{~d} 1$ and $\mathrm{d} 2$ were carried out, and the results are listed in Table 4-6. 
TABLE 4 Variance analysis results of d0

\begin{tabular}{|c|c|c|c|c|c|}
\hline Source & Square sum & Dof & $\begin{array}{c}\text { Mean square } \\
\text { value }\end{array}$ & F value & $\mathrm{P}>\mathrm{F}$ \\
\hline Model & 2.75 & 14 & 0.6973 & 420.9 & $<0.001$ \\
\hline A & 0.94759 & 1 & 0.94759 & 568.7 & $<.0001$ \\
\hline B & 0.00077 & 1 & 0.00077 & 0.46 & 0.7646 \\
\hline C & 0.00136 & 1 & 0.00136 & 0.879 & 0.7032 \\
\hline D & 0.00211 & 1 & 0.00211 & 1.18 & 0.6674 \\
\hline AB & 0.0000 & 1 & 0.0000 & 0.00 & 1.0000 \\
\hline AC & 0.00558 & 1 & 0.00558 & 3.39 & 0.4916 \\
\hline AD & 0.03676 & 1 & 0.03676 & 25.56 & 0.0416 \\
\hline BC & 0.00437 & 1 & 0.00437 & 2.62 & 0.5735 \\
\hline BD & 0.00249 & 1 & 0.00249 & 1.47 & 0.6317 \\
\hline CD & 0.00576 & 1 & 0.00576 & 3.51 & 0.4707 \\
\hline Residual & 0.0240 & 14 & 0.01792 & -- & -- \\
\hline Total & 2.7728 & 28 & -- & -- & -- \\
\hline
\end{tabular}

TABLE 5 Variance analysis results of $d 1$

\begin{tabular}{|c|c|c|c|c|c|}
\hline Source & Square sum & Dof & $\begin{array}{c}\text { Mean square } \\
\text { value }\end{array}$ & F value & $\mathrm{P}>\mathrm{F}$ \\
\hline Model & 2.11 & 14 & 0.632 & 400.16 & $<0.001$ \\
\hline $\mathrm{A}$ & 0.9016 & 1 & 0.9016 & 467.3 & $<0.001$ \\
\hline $\mathrm{B}$ & 0.000422 & 1 & 0.000422 & 0.237 & 0.8691 \\
\hline $\mathrm{C}$ & 0.003726 & 1 & 0.003726 & 2.17 & 0.6926 \\
\hline $\mathrm{D}$ & 0.005955 & 1 & 0.005955 & 3.653 & 0.5895 \\
\hline $\mathrm{AB}$ & 0.000498 & 1 & 0.0004986 & 0.220 & 0.8752 \\
\hline $\mathrm{AC}$ & 0.000630 & 1 & 0.000630 & 0.375 & 0.8535 \\
\hline $\mathrm{AD}$ & 0.0099 & 1 & 0.0099 & 0.086 & 0.9254 \\
\hline $\mathrm{BC}$ & 0.00571 & 1 & 0.00571 & 2.41 & 0.6527 \\
\hline $\mathrm{BD}$ & 0.0542 & 1 & 0.0542 & 30.71 & 0.0216 \\
\hline $\mathrm{CD}$ & 0.000632 & 1 & 0.000632 & 0.15 & 0.8821 \\
\hline Residual & 0.02511 & 14 & 0.01765 & -- & - \\
\hline Total & 2.16 & 28 & -- & -- & - \\
\hline
\end{tabular}

TABLE 6 Variance analysis results of $\mathrm{d} 2$

\begin{tabular}{|c|c|c|c|c|c|}
\hline Source & Square sum & Dof & Mean square value & F value & P $>$ F \\
\hline Model & 1.90 & 14 & 0.6839 & 450.7 & $<0.001$ \\
\hline A & 0.871 & 1 & 0.871 & 397.5 & $<0.001$ \\
\hline B & 0.000745 & 1 & 0.000745 & 0.42 & 0.9032 \\
\hline C & 0.00142 & 1 & 0.00142 & 0.88 & 0.8359 \\
\hline D & 0.00099 & 1 & 0.00099 & 0.71 & 0.8905 \\
\hline AB & 0.00246 & 1 & 0.00246 & 1.36 & 0.7855 \\
\hline AC & 0.00141 & 1 & 0.00141 & 0.871 & 0.8378 \\
\hline AD & 0.00187 & 1 & 0.00187 & 0.935 & 0.8260 \\
\hline BC & 0.00355 & 1 & 0.00355 & 2.145 & 0.4536 \\
\hline BD & 0.0061 & 1 & 0.0061 & 4.09 & 0.3658 \\
\hline CD & 0.021 & 1 & 0.021 & 18.75 & 0.0457 \\
\hline Residual & 0.01477 & 14 & 0.0141 & -- & -- \\
\hline Total & 2.01 & 28 & -- & -- & -- \\
\hline
\end{tabular}


From the results of Table 4-6, it's easy to find that F value were 420.9, 400.16 and 450.7, and the corresponding " $\mathrm{P}>\mathrm{F}$ " value are much less than 0.05. It proved that the three models had higher significantly, which can describe the relationship between the target and the design variables well.

To further verify the reliability of the model, the $\mathrm{R}^{2}$ and $\mathrm{R}^{2}$ adj tests are needed. Larger $\mathrm{R}^{2}$ and $\mathrm{R}^{2}$ adj indicate better fitting degree and more reliable respond surface function. The $\mathrm{R}^{2}$ value of three models are $97.65 \%, 97.90 \%$ and $92.33 \%$, which shows that the prediction accuracy is very high.

TABLE 7 Determine coefficient analysis of three target quantity

\begin{tabular}{|c|c|c|c|}
\hline Targets & R2 & $\begin{array}{c}\text { Adjusted } \\
\text { R2 }\end{array}$ & $\begin{array}{l}\text { Predicted } \\
\text { R2 }\end{array}$ \\
\hline $\mathrm{d} 0$ & 0.9765 & 0.9623 & 0.8857 \\
\hline $\mathrm{d} 1$ & 0.9790 & 0.9811 & 0.9175 \\
\hline $\mathrm{d} 2$ & 0.9233 & 0.9142 & 0.8536 \\
\hline
\end{tabular}

The variance analysis results in Table 4-6 can be used to compare the effect of different interaction factors on the optimization objectives. Under the four factors interaction, the most significant interaction factor for $d 0$ was $L_{1 x} * L_{4 z}$, and $L_{2 x} * L_{4 z}$ for $d 1, L_{3 z} * L_{4 z}$ for $d 2$.

In order to further study the influence of different locator layout on the optimization objective, the most significant interaction factor for $\mathrm{d} 0, \mathrm{~d} 1$ and $\mathrm{d} 2$ were chosen respectively to conduct analysis. Figure 4 shows the 3D response surfaces and the 2D contour plots. The 3D response surfaces illustrate the mutual influence on strength, while the 2D contour plots demonstrate the reciprocal interactions among the parameters. The more circular the contours are, the less significant the interaction impact is. On the contrary, the more elliptical the contours are, the more significant the interaction is [10].
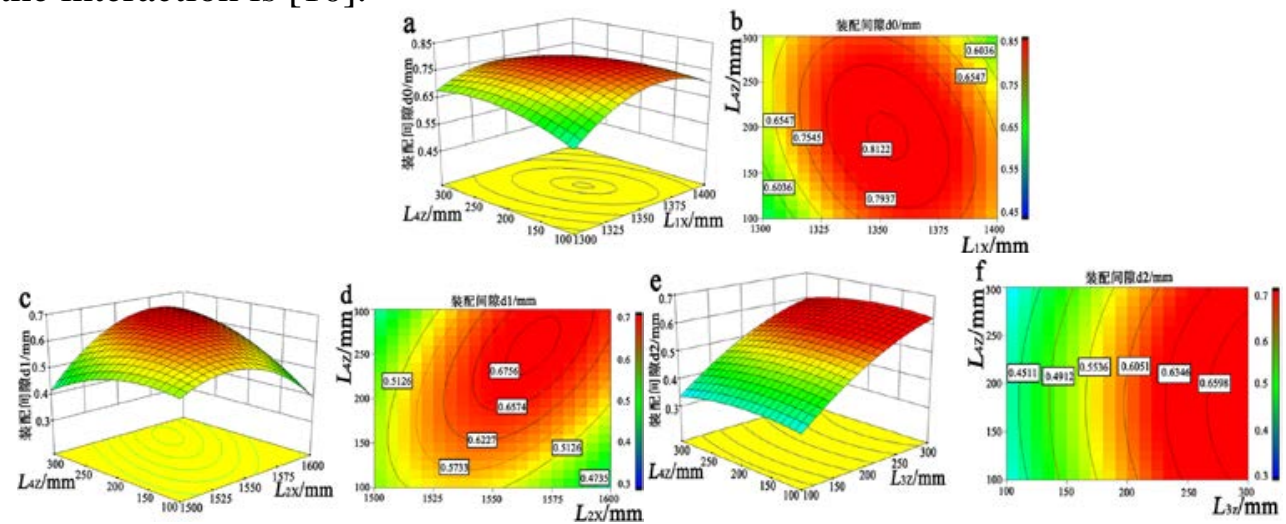

Fig. 4 Contour images of $\mathrm{d} 0, \mathrm{~d} 1, \mathrm{~d} 2$

\section{EXPERIMENT OPTIMIZATION AND VALIDATION}

On the basis of the experimental analysis and model fitting, the Design-Expert8.0 software is used to optimize the coordinate parameters of the locating block [7]. Limit d0, d1 and d2 in the range of $\pm 0.5 \mathrm{~mm}$, four groups of optimization scheme were obtained in Table 8 . The predictive values are the response values obtained by the response surface optimization and the simulation values are the results of the finite element simulation. The error is calculated by (5) in the below:

$$
e=\left(e_{1}-e_{2}\right) / e_{1} \text {. }
$$


TABLE 8 Coordinate parameters for verification and result

\begin{tabular}{|c|c|c|c|c|c|c|c|c|}
\hline & \multicolumn{4}{|c|}{ Coordinate parameters } & \multirow[b]{2}{*}{ results } & \multicolumn{3}{|c|}{ Response factor } \\
\hline & $\begin{array}{l}\mathrm{A} / \mathrm{m} \\
\mathrm{m}\end{array}$ & $\begin{array}{l}\mathrm{B} / \mathrm{m} \\
\mathrm{m}\end{array}$ & $\begin{array}{l}\mathrm{C} / \mathrm{m} \\
\mathrm{m}\end{array}$ & $\begin{array}{l}\mathrm{D} / \mathrm{m} \\
\mathrm{m}\end{array}$ & & $\mathrm{d} 0 / \mathrm{mm}$ & $\mathrm{d} 1 / \mathrm{mm}$ & $\begin{array}{l}\mathrm{d} 2 / \mathrm{m} \\
\mathrm{m}\end{array}$ \\
\hline \multirow[t]{3}{*}{1} & \multirow{3}{*}{$\begin{array}{l}132 \\
5\end{array}$} & \multirow{3}{*}{$\begin{array}{l}156 \\
5\end{array}$} & \multirow{3}{*}{251} & \multirow[t]{3}{*}{342} & $\begin{array}{l}\text { Predictive } \\
\text { value e1 }\end{array}$ & 0.4561 & 0.4711 & 0.4764 \\
\hline & & & & & $\begin{array}{l}\text { Simulation } \\
\text { value e2 }\end{array}$ & 0.4196 & 0.4956 & 0.4427 \\
\hline & & & & & Error e/\% & 7.91 & -4.9 & 7.13 \\
\hline \multirow[t]{3}{*}{2} & \multirow{3}{*}{$\begin{array}{l}136 \\
0\end{array}$} & \multirow{3}{*}{$\begin{array}{l}157 \\
8\end{array}$} & \multirow{3}{*}{271} & \multirow{3}{*}{310} & $\begin{array}{l}\text { Predictive } \\
\text { value e1 }\end{array}$ & 0.4157 & 0.4019 & 0.4538 \\
\hline & & & & & $\begin{array}{l}\text { Simulation } \\
\text { value e2 }\end{array}$ & 0.4025 & 0.4275 & 0.4267 \\
\hline & & & & & Error e/\% & 3.18 & -6.07 & 5.98 \\
\hline \multirow[t]{3}{*}{3} & \multirow{3}{*}{$\begin{array}{l}137 \\
5\end{array}$} & \multirow{3}{*}{$\begin{array}{l}156 \\
0\end{array}$} & \multirow{3}{*}{325} & \multirow{3}{*}{349} & $\begin{array}{l}\text { Predictive } \\
\text { value e1 }\end{array}$ & 0.3956 & 0.3912 & 0.4102 \\
\hline & & & & & $\begin{array}{l}\text { Simulation } \\
\text { value e2 }\end{array}$ & 0.3815 & 0.4007 & 0.3897 \\
\hline & & & & & Error e/\% & 3.56 & -2.37 & 4.99 \\
\hline
\end{tabular}

The three groups of optimization schemes were calculated and the error were all within the range $\pm 8 \%$. It shows that the results obtained by the response surface optimization are of high reliability. The error in the 3rd scheme was relatively smaller, only in the range of $\pm 5 \%$, therefore, this scheme can be considered as the best optimal scheme. The 3DCS software is used to simulate the scheme [10]. The data are analyzed and compared in Table 9.

TABLE 9 The results comparison of the initial design and optimal design

\begin{tabular}{|c|c|c|c|c|}
\hline Scheme & Result & $\mathrm{d} 0 / \mathrm{mm}$ & $\mathrm{d} 1 / \mathrm{mm}$ & $\mathrm{d} 2 / \mathrm{mm}$ \\
\hline \multirow{3}{*}{$\begin{array}{c}\text { Original } \\
\text { design }\end{array}$} & Nominal & 0 & 0 & 0 \\
\cline { 2 - 5 } & Mean & 0.5027 & 0.4911 & 0.4765 \\
\cline { 2 - 5 } & $\begin{array}{c}\text { Tot-OUT } \\
\%\end{array}$ & 0.31369 & 0.2673 & 0.3638 \\
\hline \multirow{4}{*}{$\begin{array}{c}\text { Optimization } \\
\text { design }\end{array}$} & Nominal & 0 & 8.40 & 8.35 \\
\cline { 2 - 5 } & Mean & 0.3256 & 0.3785 & 0.3676 \\
\cline { 2 - 5 } & 6 & 0.22195 & 0.15385 & 0.21366 \\
\cline { 2 - 5 } & $\begin{array}{c}\text { Tot-OUT } \\
\%\end{array}$ & 3.75 & 4.15 & 4.20 \\
\hline
\end{tabular}

It can be seen from Table. 9, the superb rate decrease significantly through multi-objective optimization. According to Table 9, d0, d1 and d2 decrease 35.2\%, 22.9\% and 23.6\% respectively; the corresponding superb rate reduce $58.3 \%, 50.6 \%$ and $49.7 \%$; the standard deviation of $\mathrm{d} 0, \mathrm{~d} 1$ and d2 cut down to $29.3 \%, 42.4 \%$ and $41.4 \%$.

\section{CONCLUSION}

(1)In view of the problems existing in the assembly quality of B pillar, the mathematical model of side-body outer panel between locating parameters and assembly quality was established combined with the 3DCS numerical simulation and the response surface method.

(2)The Design-Expert8. 0 software was used to optimize the locating parameters, finally the optimal parameters combination were obtained, namely e L1x=1375 mm, L2x=1560 mm, L3z=325 $\mathrm{mm}, \mathrm{L} 4 \mathrm{z}=349 \mathrm{~mm}$. The feasibility of the method is verified by numerical simulation and practical production.

(3)Combining the response surface method with the numerical simulation technology, it is applied to the dimension engineering, which provides a new method for the low cost and high 
quality production of B pillar, and provides some guidance for the practical production.

\section{ACKNOWLEDGMENT}

The author acknowledges that support was received from the Fundamental Research Funds for the Central Universities (No. CDJZR13130082).

\section{REFERENCES}

[1] W. D. Liu, R. X. Ning, J. H. Liu, et al. Mechanism Analysis of Deviation Sourcing and Propagation for Mechanical Assembly [J]. Journal of mechanical engineering, 2012, 48(1): 156-168.

[2] W. Wei, C. Guo, X. D. Duan. Research on tolerance constraint based assembly method in virtual assembly [J]. Computer Engineering \& Science, 2013, 35(6): 162-173.

[3] K. G. Yu, H. Z. Yang. Tolerance design of automotive body sheet metal parts based on a compliant assembly variation model [J]. Journal of Shandong University: Engineering Science, 2014, 44(3): 69-74.

[4] P. Kim, Y. Ding. Optimal Design of fixture layout in multi-station assembly processes [J]. IEEE Transaction Automation science and Engineering, 2004, 1(2): 133-145.

[5] W. Cai. Robust pin Layout Design for Sheet-panel Locating [J]. The International Journal of Advanced Manufacturing Technology, 2006, 28 (5): 486-494.

[6] W. Z. Huang, Z. Y. Kong, A. Chennamara. Robust Design for Fixture Layout in multi-station assembly systems using sequential space Filling Methods [J]. Journal of Computing and Information Science in Engineering, 2010, 10(4): 001-011.

[7] Z. J. Wen, F. Zhang, H. C. Liu, et al. Robust Pinhole Layout Design for Car Light Cover Assembly Based on Taguchi orthogonal experiment and 3DCS[J], Chinese Journal of Automotive Engineering, 2013, 3(4): 275-281.

[8] M. N. Mohamed, A. A. Amgad, S. Hamdani, et al. Optimization of reaction parameters of radiation induced grafting of 1-vinylimid azole onto poly using response surface method [J].Radiation Physics and Chemistry. 2011, 80: 1222-1227.

[9] Y. F. Xia, X. H. Yang, X. K. Zheng, et al. Multi-object optimization of incremental hot bending process of hook tail frame based on RSM [J]. Journal of Central South University (Science and Technology), 2014, 45(9):2977-2984.

[10] X. H. Xu. Study of Tolerance Analysis Method and Application Based on 3DCS [D]. Shandong: Shandong University, Department of Mechanical Engineering, 2012. 